\begin{tabular}{c|c|c}
\hline \hline & MARINE ECOLOGY PROGRESS SERIES \\
Vol. 228: 1, 2002 & Mar Ecol Prog Ser & Published March 6 \\
\hline
\end{tabular}

\title{
A WORD FROM THE PUBLISHER
}

\section{Importance and organisation of direct post-publication critique}

\author{
Otto Kinne* \\ Inter-Research, Nordbünte 23, 21385 Oldendorf/Luhe, Germany
}

Science assists in forming the basis for the orderly development of our societies and in planning our future. It affects the way in which we live and the chances for human survival. An increasing number of articles published in Inter-Research (IR) joumals are related to these important issues. Hence the data, facts and ideas presented in such articles, as well as possible differences in their interpretation and impact assessment, require rigorous in-depth consideration. Such rigour should not only focus on the review processes prior to publication, but also on direct post-publication critique.

For direct post-publication critique, IR has developed, and offers in its journal pages, opportunities for exchanges of Comments and Reply Comments. Comments comprise critical reassessments of published work. Reply Comments present answers from the author(s) criticised.

The purpose of direct post-publication critique is the enforcement of 'truth finding'. Even a very thorough review process cannot include all essential perspectives and it cannot exclude mistakes or misjudgements. IR therefore gives readers the opportunity to criticise IR-published articles, i.e. to point out needs for correction, amendment, re-evaluation or improvement. We invite criticised authors to publish their defence, e.g. to acknowledge their own mistakes, to point out misinterpretations or failures in the Comment itself and possibly to present new insights. Post-publication critique alerts the international scientific community to failures, contradictions or differing views and it stimulates readers' own thought and allows them to draw their own conclusions.

In order to organise Comment/Reply Comment exchanges properly, certain prerequisites and rules have to be observed:

(1) Comments must have scientific substance and avoid personal attacks. They should be fair and brief (generally no longer than 1 to 3 printed pages).

(2) The publisher must inform the criticised author(s) of a forthcoming Comment.

(3) Authors of Comments must agree that IR makes their final Comment text available to the author(s) criticised prior to publication.

(4) Criticised author(s) should then write and submit their response swiftly.

(5) Both parties involved must agree that the postpublication critique ends with this exchange, i.e. no 'ping-pong' battles!

(6) Wherever possible, Comment and Reply Comment are to be published side by side in the journal in which the original article appeared.

There may be a temptation to use Comment/Reply Comment exchanges as a stage for elaborating on conflicts of interest, for political, technological or legal disputations, or as an instrument for personal revenge. We do not support such misuse and Editors must help to prevent it.

*E-mail: kinne@int-res.com 